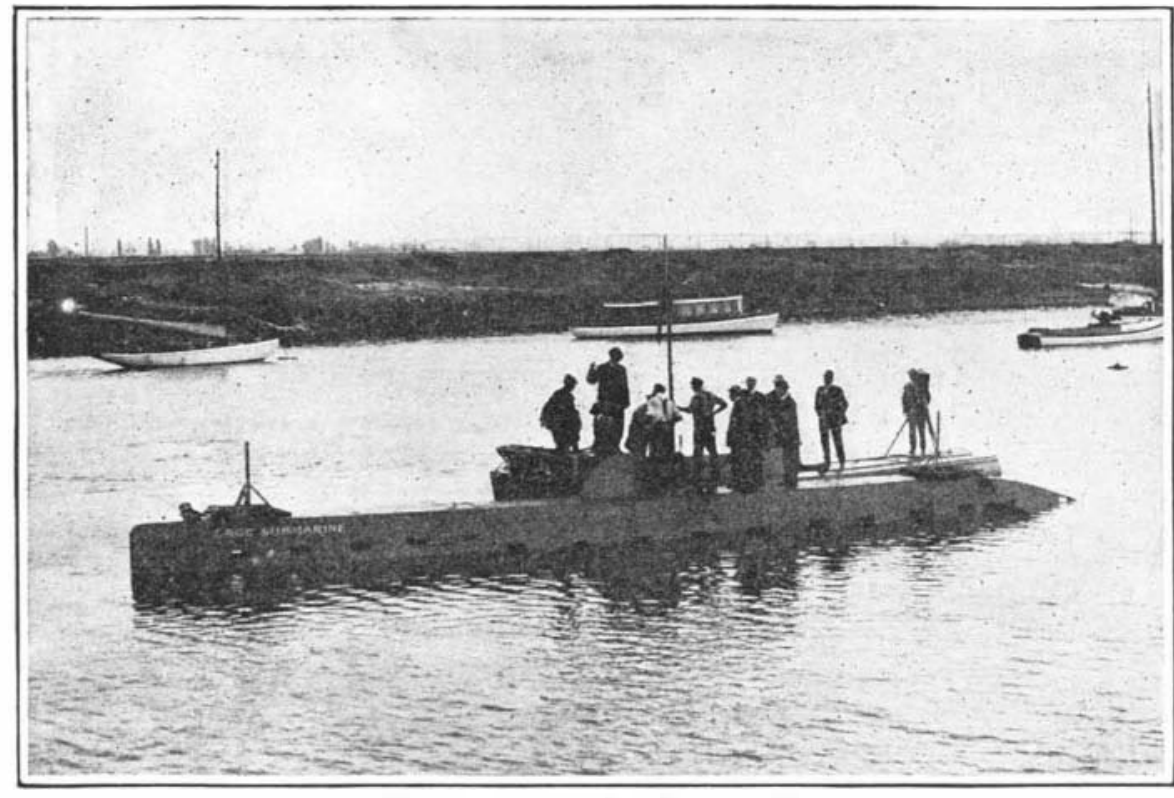

The Cage submarine in the water

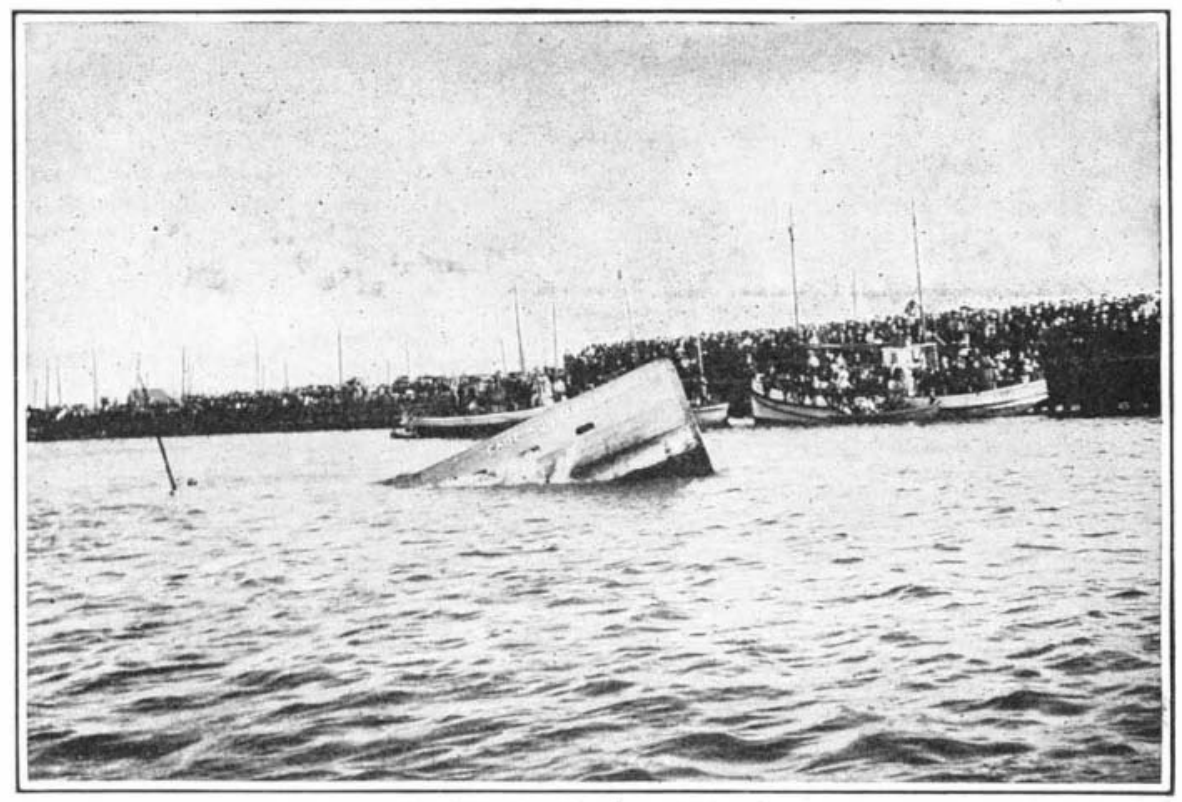

Caught in the act of diving

\title{
Gas Engine Drive For Submerged Submarines
}

\section{A California Experiment Which Aims To Supplant the Storage Battery}

\author{
By F. C. Crossman
}

FOR running submerged the storage battery is not engineering, but it represents the only avenue of attack upon the problem which has as yet led to results of practical value. Yet any submarine engineer with a broad vision of the future would admit, if you could but probe into his innermost secret soul, that while the storage battery is good enough to make submarine warfare a fact, it possesses drawbacks so serious as to render it out of the question-for him to believe that it can stand permanently as the last word in sub-surface navigation. In first class condition and under first class conditions it is reliable enough. But a submarine when submerged furnishes almost ideally all the conditions under which a storage battery should not be operated. Insufficient ventilation, insufficient air for breathing, odors of oil, finely divided oil particles in suspension, battery gases and the odors of humans themselves, all conspire to produce a species of sea-sickness and general loginess that take from the efficiency of the crew. Under these circumstances, the evils of the long rows of acid-filled tanks, the gassing that takes place or threatens to take place during charging or discharging, become very real perils.

Moreover, as submarine warfare proceeds, it becomes increasingty clear that the ideal submarine must work under water more swiftly than the present storagebattery drive makes possible. The successful sub operates precisely as does the successful burglar or highwaymanstealthy but quick approach, the attack, and the prompt get-away before the minions of the law can arrive in response to the wild shrieks of the attacked. It is not healthful in these days for the submarine to lie dead on the bottom for a day or so because when it comes to the top for a look-see or a supply of air there is the hopeful little boat with the hopeful little cannon waiting to plunk it and the hopeful little net waiting to tangle it up. High speed for a couple of hours spells the only sure safety for the shark, and high speed submerged is precisely what the electric storage battery cannot deliver. Every layman knows now that the storage battery, discharged rapidly as when the motors are driven at high speed, has a life better measured in seconds than in hours. With these facts marshalled before us, the following quotation from a Lausanne, Switzerland, press despatch is interesting. It refers, of course, to German procedure.

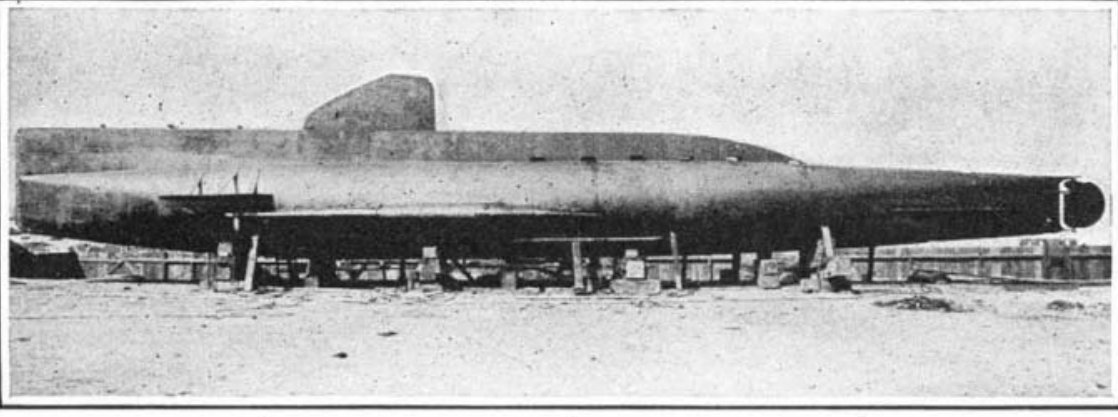

The Cage boat out of the water, showing her lines

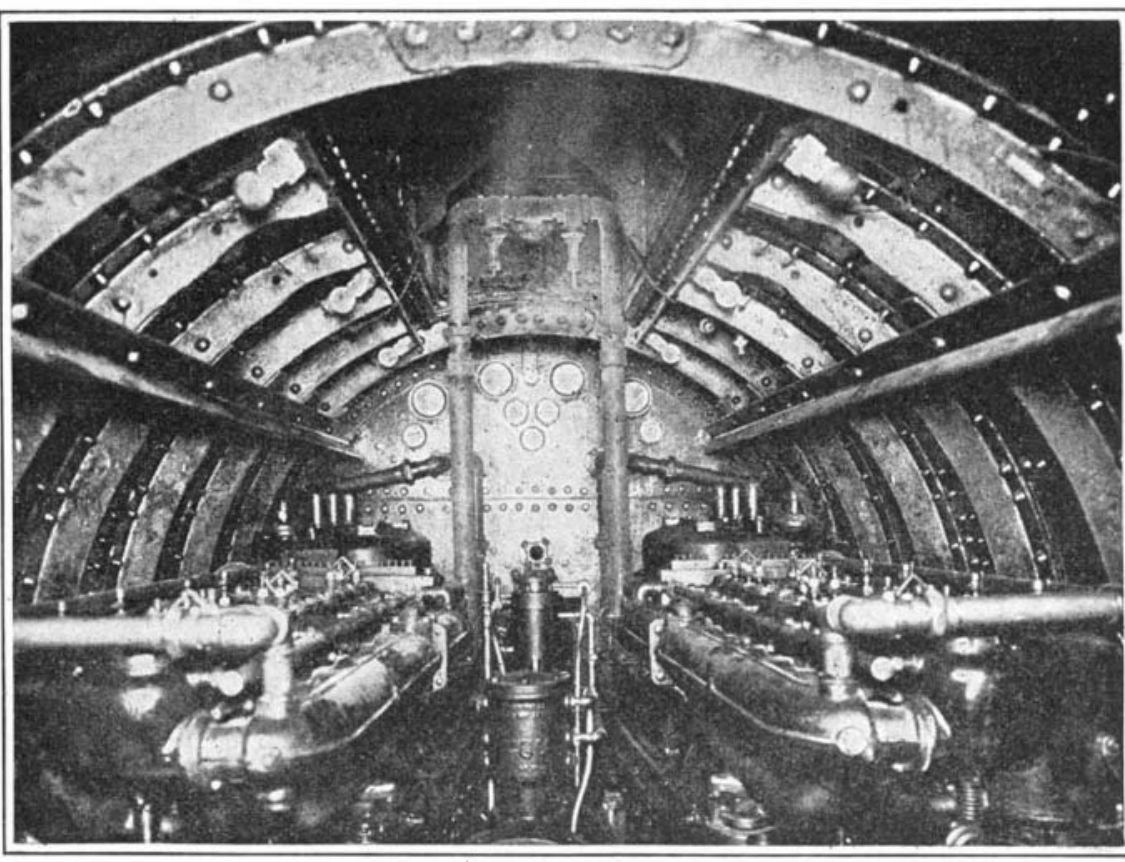

The operating mechanism of the Cage submarine, predecessor of the Neff boat. The pump in the center was not part of the permanent machinery illustrated this story from pictures of its predecessor, which it resembles very closely in all respects except that it is expected to run. The Cage boat displayed an alarming fondness for going to the bottom head-on and then trying to dig in, but during its moments on an even keel, the Navy board which investigated it became convinced of the feasibility of driving submarines submerged with the gas engine.

The gas engine has just two fatal habits that have thus far made it taboo for the boat under water. One is that it uses all the air there or thereabouts, which doesn't matter when air is plentiful. The other is that it has a bad breath and lots of it, which also doesn't matter when the whole outdoors is available for the dispersion of said breath.

So the first change in the standard submarine machinery-outside of derricking out the batteries and motors-is the installation of a pair of powerful air compressors driven off the main engine shafts, and then batteries of hundreds of airflasks akin to the heavy tanks used for storing carbonic acid gas for the soda fountain. These flasks, holding air at a pressure of 3,000 to 3,500 pounds per square inch, are stored in the space formerly given up to the batteries, and in the spare space in the superstructure. A change to this type of boat would make redesigning the interior for the accommodation of air bottles a necessity for the best results.

In a boat of say 500 tons the presen battery installation requires about 1,150 cubic feet. The air tank installation requires 1,700. But, where the batteries weigh with their motors about 200,000 pounds the air equipment weighs 160,000 , a saving of 20 tons.

This is the air equipment to care for the greedy lungs of the big engines.

To put its breath overboard against the heavy pressure of the sea-water, a simple double-acting force-pump is utilized, and the motive power thereof is derived from the energy stored in the compressed air. This force pump, "mechanical exhauster," as Mr. Neff terms it, driven by the high pressure air from the tanks, takes all work off the engine, and puts the exhaust overboard without any back-thrust on the engine and any consequent loss of power. In detail, with the air tanks full, the boat submerges and the air-intake pipe on the conning tower closes automatically against the entrance of sea-water. Air commences to flow from the great battestimony of various navy men, including the Secretary tery of tanks through a reducing valve to bring it down of the Navy himself, as to the desirability of doing away to the more civilized pressure of about 150 pounds per with the battery, and the chances that the Neff plan square inch. As it is cold it is then passed through a would be a success. Wherefore from the despatch de- reheater, which in turn is heated by the engine exhaust; tailing the German adoption of this plan, and the Amer- and its temperature is again raised to about 400 degrees. ican resolve to go ahead with the working out of the Then it is led to the motor cylinders of the mechanical

plan, it would appear that the old storage battery has a exhauster or force-pump. fine prospect of meeting early competition.

The Neff plan of submarine propulsion is based on the Cage design, which was tried out in a very crude 75-foo submarine built in California some years ago. In the

absence of any photographs of Mr. Neff's boat we have
Its work done, the air is then passed through suitable mufflers to remove the pulsation and through oil separators by which all oil vapors are removed, then it is turned into the interior of the boat by various outlet valves.

$$
\text { (Concluded on page 146) }
$$

Queerly enough-this appeared some months after $\mathrm{Mr}$. A. R. Neff, an American submarine man, formerly with inferior to that of rapid mail packets." 


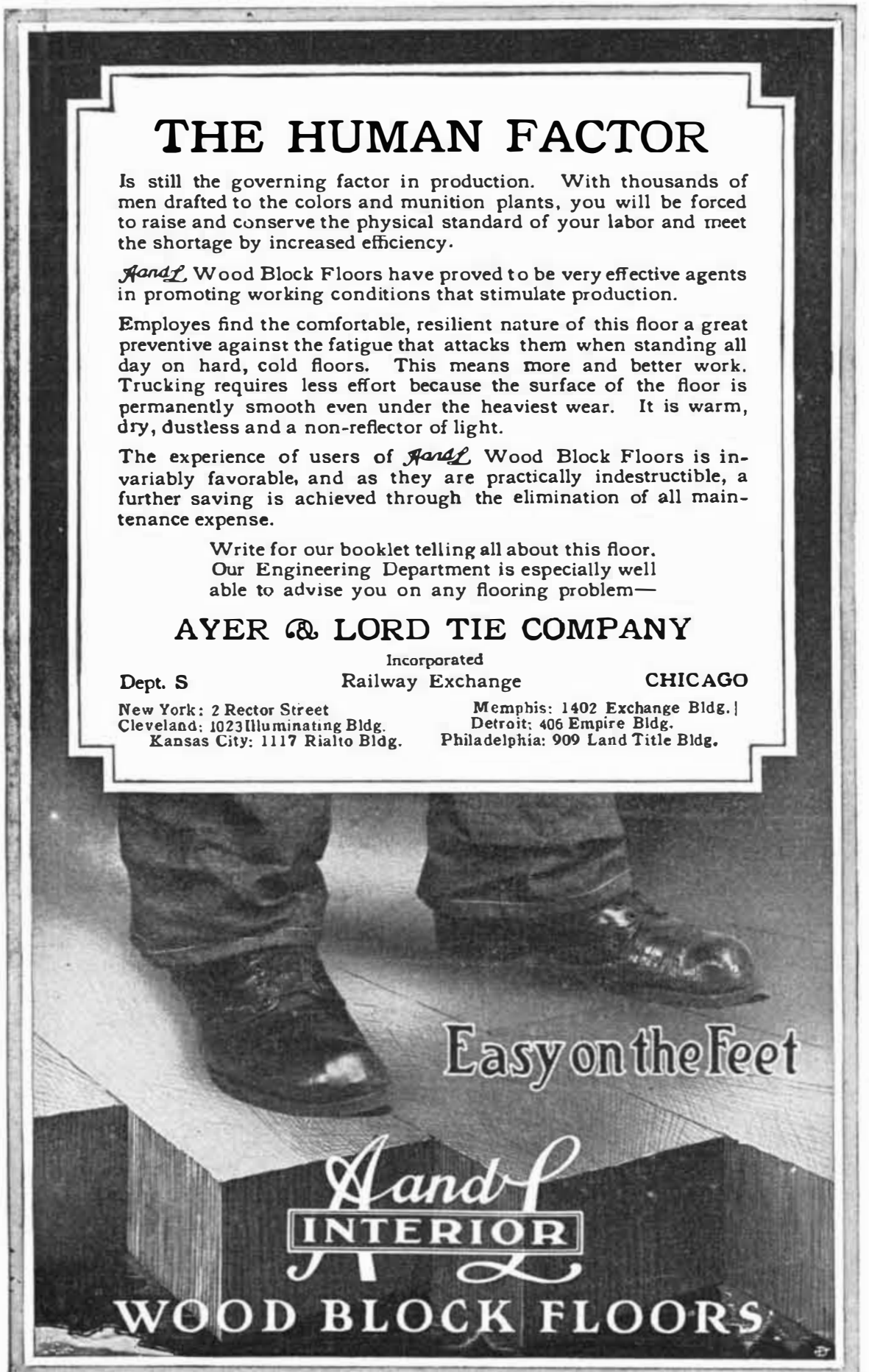

NOW READY!

New 1916 Revised and Enlarged Edition. Showing all Recent Improvements

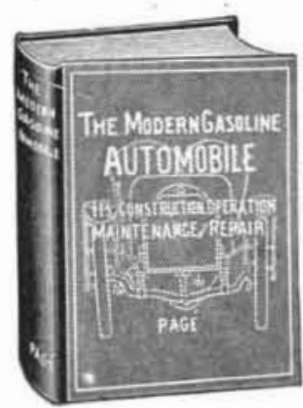

The Modern

Gasoline Automobile

\author{
Its Construction, Operation, Mrintennee and Repair \\ By, VICTOR W. PAGE, M.E \\ Covers Every PBase of Moden Automobile Practice. Latest and \\ Orer $850(5 \% / 2 \times 8)$ Pages
12 LARGE FOLDING PLATES
}

Price \$2.50 Postpaid

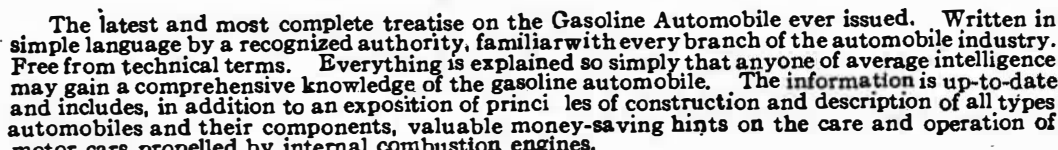

IN THE 1916 REVISED EDITION

The subject of electrical motor starting systems has been conThe at length and all leading systems and their.components de scribed. A discussion on ball and roller bearing, their main tenance and installation, has also been included, and a number of other features of timely interest such as latest types of gasoline and kerosene Carburetors, cyclecar power plants, the pischer slide valve motor detachable wire wheels, cantiever springs, eight and twelve-cylinde mor

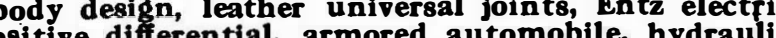
transmission

Entirely new material has been added on tractors in three and plows; combination gasoline-electric drive, front-wheel and four-
wheel drive and steer systems and other important developments in power-propelled vehicles. The discussion of power transmission power-propelled vehicles. The discussion of power transmission gear and two-speed direct drive rear axle, as well as several new forms up to date.

This book is euperior to any treatise pablinhed

Not too Technical for the Layman-Not too Elementary for the More Eptre Sent prepeid to aps address on receipt of price

MUNN \& COMPANY, Inc., 233 Broedway, Woolworth Building, Now York

\section{The Neglected Water Power of} New England (Concluded from page 14t)

ironed by these wires, while other lines are planned to cover southern Vermont and New Hampshire, northern Connecticut, and even Rhode Island. At the presen line is in operation from Shelburne Falls via Ware and Millbury to Worcester, thence to Fitchburg, Gardner and Brattleboro, and back to the starting point via Hinsdale. This loop is continually bein expanded. From North Adams a lin is planned to run north to the cotton and woolen mills of Bennington, and anothe southward to those of Pittsfield. From Uxbridge an extension is projected to reach Providence and Pawtucket, in spite or the tide-water coal. From Fitchburg a third line will run to the mills of Nashua and line will

In this way the hydro-electric engineer is steadily putting his network over all New England. The only serious competitor which he has in his field is the tidewater coal just mentioned. Boston, for example, secures its industrial coal at $\$ 3.50$ per ton, and at this figure can develop its own electric power at somewhat lower cost than that of bringing in the current from the Connecticut Valley. But even if this should be a permanent dis advantage, it is not sufficient to keep the natural power from claiming its rightfu place. The vital element is that the State Commissions of the various state are giving concerted and systematic investigation and publicity to the subject. Manufacturers, investors and engineers are being brought to careful consideration of a theme that has hitherto escaped them All in all, New England's adequate de velopment of her natural power resources if slow in coming, seems now to be correspondingly sure.

\section{Gas Engine Drive for Submerged} Submarines

\section{Concluded from page 132)}

Aft, the suction of the big engine draws the air to its intake, creating a steady draft through the boat. The amount used by the engine is of course far in excess of the needs of the crew, and the men therefore work in a constantly renewing air supply. The air supply turned into the boat is regulated by the demands of the engines, the pressure is kept at about that of the atmosphere.

The engine exhaust, after serving to heat the air from the tanks in the before-mentioned reheating device, is passed into a water-cooled condenser outboard, where it is cooled and contracted. Then it is drawn into the cylinders of the exhauster and driven out of the boat through a cla shell valve opening close to the keel.

There is, therefore, an excess of fresh air in the boat at all times, instead of the stinking, dead atmosphere of oil particles and battery gas and evil smells. No gas or dead air pockets can form with the steady draft through the hull of the boat.

Mal de mer is largely done away with.

The military advantage of the plan, outside of the greater efficiency of the crew, is that instead of the power of the boat being reduced from say 1,000 horse-power on the surface to 500 horse-power when the change to the electric drive is made, practically the full power of the engine remains available. Instead of reducing the propeller size from the standard which would be correct for the gas engine in order to temper it to the weakness of the storage battery, the propellers are left the correct size for the thews and sinews of the mighty gas engines. The boat develops the same power, and almost the same speed submerged as when on the surface

Where the storage battery would deliver not to exceed an hour's run at the maximum speed of 10 miles per hour, the gas engine driven boat can develop 14 miles per hour for two hours.

When the question becomes one of loafing, the battery has a bit the best of it-but of course the condition of the crew is not taken into consideration at the end of the time. Where the airtank installa- tion now contemplated permits the boat to cruise 11 hours at 5 knots, the batterydriven boat can cruise 15 hours at the same rate. Alteration of design and the utilization of every possible bit of room for the tanks would lengthen this time and also add to the time the boat could maintain its maximum speed.

The Navy submarine man, shown the plan of this type of engine, invariably spots as the Ethiopian in the wood pile the posibility that the presence of the boat might be given away by a wake of gas and oil bubbles. Needless to say if a submarine goes around very long leaving a neat ittle trail of gas bubbles and oil slick, ome tickled submarine chaser will alight on the scent, cruise along to leeward with he 3-incher cocked and primed and be right on the job when the shark sticks out its dorsal fin. Also there is the matter of noise.

To this Mr. Neff replies as he replied to the Congressional Committee, that the exhaust is sent out of the sea-valve at a pressure little more than that of the water, and there is no characteristic noise of exhaust to give away the boat. Furthermore the noise is merely the common reciprocating murmur of the engines used by most surface craft, and the high pitched whine of the electric motor; to which the microphones of the submarine chasers are attuned, is absent." A posible one of the many rich jokes Fritz will have to spring after the war is that of the latest German submarines sliding under the keels of chasers who are listening only for the whine of electric motors, not the murmur of the gas engine.

The exhaust gases, after being cooled and condensed, are driven out of a clamshell valve in the bottom of the boat and forward of the propellers. The rush of water into the forward end of the valve sprays the gas and it is taken by the rush of water along the bottom to the pound of the propellers, where it is beaten up much as the egg is beaten up in the whirling egg beater. The gas does not issue under pressure, and it is thoroughly mixed with ater.

The board sitting in the case of the California experimental submarine stated that it didn't notice any perceptible wake the Cage submarine when it submerged. The displacement wave of any submarine is perceptible in smooth water, and there is also a white, milky wake from the propeller beat releasing air in the water. The sole difference in the wake of the gas engine boat will probably be merely a slight increase in this milky appearance. In water rough enough to hide the displacement wave this wake is not visible; in water smooth enough to show the wake, the displacement wave is a far more accrate index to the whereabouts of the boat. A possible variation of the air tank plan, is the addition of tanks filled with pure oxygen-stated also to be used by the Germans. The exhaust is rid of its moisture and its oil, is mixed with oxygen from the tanks, and is used over and over again. The crew of course use air from the storage

The advantages of the Neff system of The summed up are:

Higher submerged speed and consequent greater power of attack and escape. creater habitability of the boat when part of the crew and greater endurance in case of long submersion. Absence of costly, short-lived and delicate batteries. Freedom from danger of gassing, and $\mathrm{fr}^{\circ} \mathrm{m}$ spilling of acid in case the boat should capsize temporarily. Economy of installation. Lesser weight. Far greater ability to keep the sea for long periods because of the greater durability of the gas engine, and the short time necessary for overhaul when that becomes desirable. Absence of the characteristic motor hum which plainly marks the passing of the submersible.

Work will start at an early date on the construction of a boat for the installation of the engines under the Navy appropriation, Mr. Neff preferring to build the boat complete, to the Navy's scheme of using one of the already existing submarines, 
necessary according to the Nav.y figures The new boat will be of course entirely experimental, but the machinery that goes in will be tested units selected after careful consultation with the greatest firms making them, from the makers of the air compressors to the builders of the engines. If the plan is a failure, it will be because of some unforseen objection, not because of any weakness that the makers of the apparatus required could foresee and prevent.

\section{The War of Specialists-The Machine Gunner (Concluded from page 137)}

and a few well wired in will hold up a division, the necessity of locating the enemy's guns and concealing your own must be apparent.

Machine guns are best used from innocent looking positions with good field of fire, such as hay cocks, behind timber, growing crops, bushes, hay ricks, bundles of sticks, etc.; that is to say, from positions which are not obviously placed where you would expect them. They are essentially weapons of opportunity and surprise. "Concealment is the best protection." In the $N$. W. corner to the Grand Place, Ypres, there is a shell hole which measures 50 feet across the mouth of the crater and 22 feet deep in the center, caused by the arrival of a 42-centimeter shell (about $171 / 2$ inches) on a hard pavé road. In another we buried thirty horses. This will show the folly of trying to build up anything strong enough to protect a machine gun from shelling. Of course emplacements are made to withstand small shells, shrapnel and bullets; but every inch put on will make an emplacement more conspicuous and any heightening above the line of a trench will be shelled therefore I cannot repeat too often "Concealment rather than protection."

Lewis guns are distinct weapons from machine guns and are used by the infantry, and in the front line-work they go ove with the second and later waves. They are inconspicuous, can be carried easily, and look at a distance like rifles. The rate of fire is quicker and more concentrated than that of a machine gun. The 47 cartridges contained in a drum are fired at the rate of 780 a minute while the gun is firing; but it is impossible to maintain that rate of fire, time being lost through the drums having to be changed.

Lewis guns are new weapons and are as distinct from machine guns as a revolver is distinct from a rifle, their only similarity being that they fire the same caliber ammunition.

Machine guns produce a narrow, dense cone of fire, therefore they should be used to a flank, fired obliquely, and fired to the front only when a favorable target appears. A bullet from a machine gun will hit a man, and hit him again ten times as he is going down; but in the case of a gun catching men obliquely you always have a target of fresh men. Machine gun training must play an important part in all new armies, and it is only the cool, reliable man with a thorough knowledge of his work and weapon that can get results. A man must know his gun as a keen motorist knows his car or a jockey his mount. The old idea that you wait for your enemy to show up in numbers, open fire, and then expect them to keep on coming, is wrong. Your work will be over in a matter of minutes and seconds and then you will have to move. On one occasion a machine gunner operating from second stories in village fighting changed his position six times, only firing five minutes from each place. In every case, inside of fifteen minutes from the time he had opened fire, the houses were shelled.

A rush of men may get past a gun, but not if it is enfilading a barbed wire or obstacles, and correctly handled. A gun in action enfilading 500 yards of wire is worth a man a yard.

\section{Starch in Santo Domingo}

$\mathrm{S}^{\text {TARCH }}$ is made in Santo Domingo by the peasants throughout all the Cibao region from the yuca or manioc root (Bot. Jatropha manihot) by a process of squeezing out the juice and then drying it.

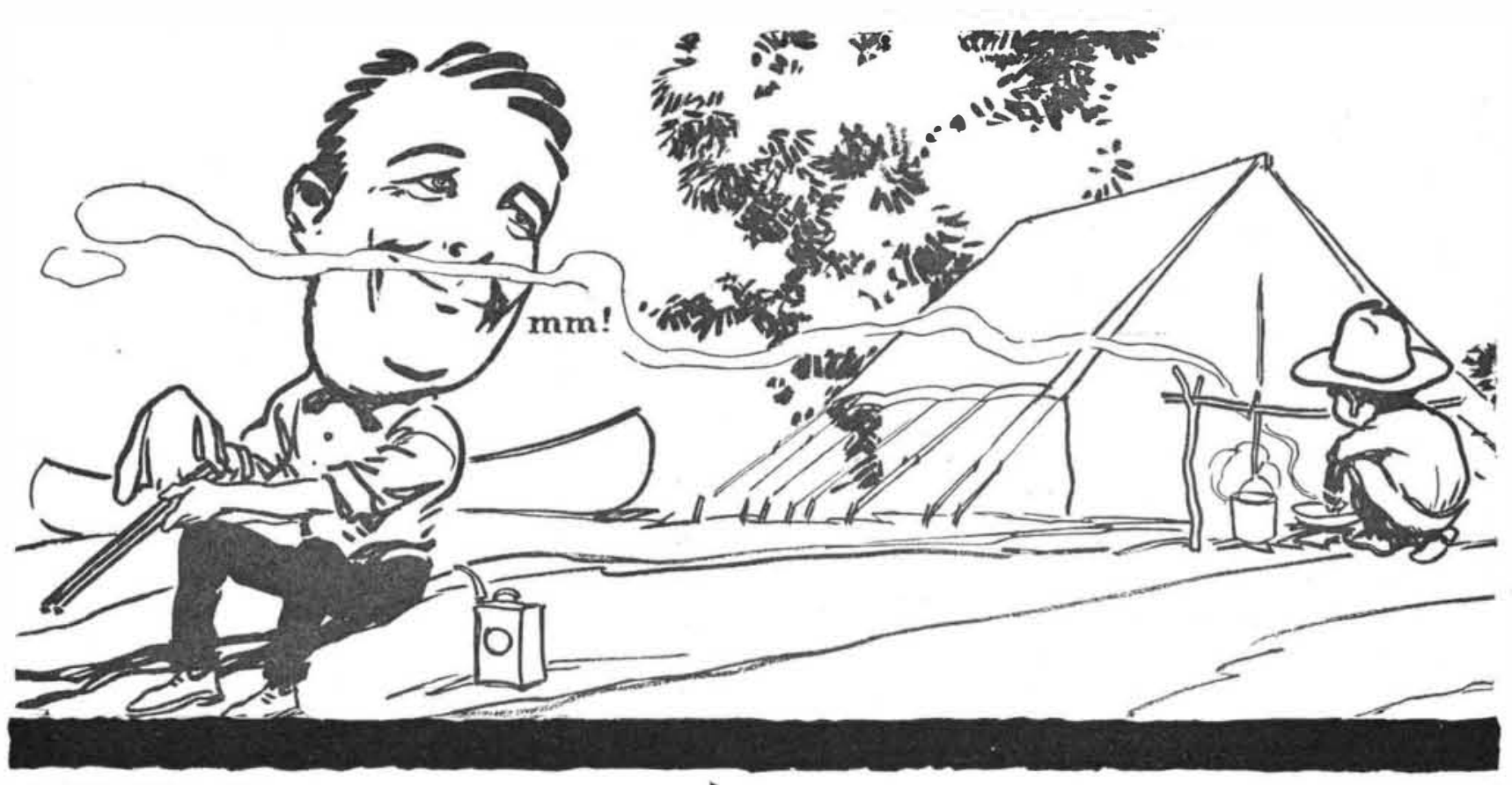

\section{HOW do you know it's Dinner Time? "rour Nose linows"}

\section{By the fragrance! How the frying bacon} whets your hungry appetite and promises a keen delight to come. Just so the pure fragrance of a good tobacco promises absolute smoke satisfaction. No sense on earth is so dependable as that of pure fragrance-"Your Nose Knows."

Such a promise you will find in

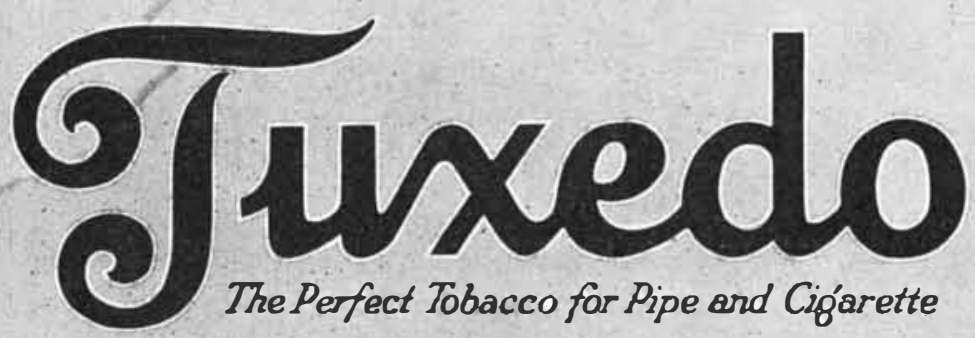

Made of the most fragrant leaves of the tobacco plant-the tender, Burley leaves, ripened in the Blue Grass sunshine of Old Kentucky, mellowed and carefully blended-Tuxedo has a pure fragrance all its own - "Your Nose Knows."

Try this Test: - Rub a little Tuxedo

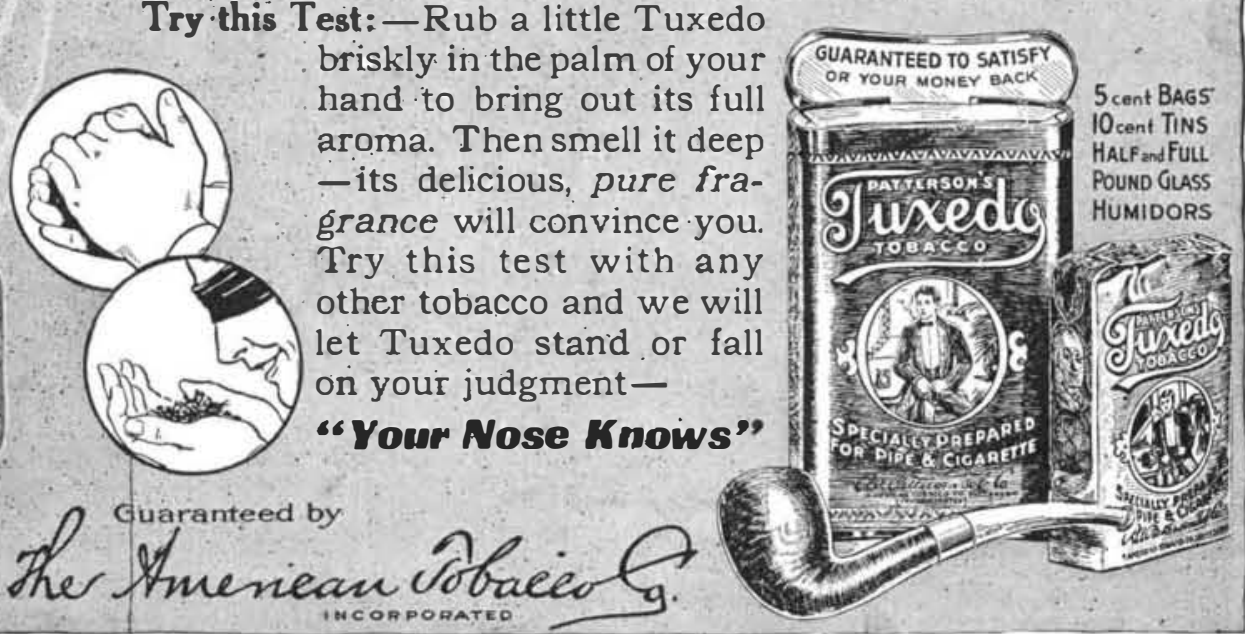

